\title{
COLABORAÇÃO COMO ESTRATÉGIA DIDÁTICA NO FÓRUM DE DISCUSSÃO NA GRADUAÇÃO ONLINE
}

\section{COLLABORATION AS STRATEGY TEACHING IN DISCUSSION FORUM ONLINE AT GRADUATION}

\section{COLABORACIÓN COMO ESTRATEGIA DE ENSEÑANZA EN FORO DE DIS- CUSIÓN EN LIINEA EN GRADUACIÓN}

\author{
Marta Teixeira do Amaral Montes \\ Professora Mestre da Universidade Estácio de Sá, Estácio Campus Virtual. \\ Doutoranda em Educação pela Universidade Federal do Rio de Janeiro. \\ marta.amaralmontes@gmail.com \\ Maria Judith Sucupira da Costa Lins \\ Professora Doutora da Universidade Federal do Rio de Janeiro. \\ mariasucupiralins@terra.com.brr
}

RESUMO: Este artigo objetiva descrever alguns resultados de uma pesquisa qualitativa que visou identificar se docentes que atuam na educação a distância utilizam práticas comunicacionais colaborativas no fórum de discussão como estratégia didática no ensino superior online. A técnica de coleta de dados foi o grupo focal e as informações coletadas foram interpretadas sob o método da análise de conteúdo. Os dados foram tratados mediante a técnica da análise temática. Os resultados apontaram que embora os professores reconheçam que a Educação a Distância - EAD é uma inovação que demanda postura docente diferenciada e novas relações com o saber, não conseguiram ainda distanciar-se completamente do exercício da pedagogia de transmissão e transpor a lógica da linearidade. A adaptação do ambiente presencial para o cenário virtual ainda é um aspecto forte na modalidade online. Os entrevistados percebem que a colaboração é uma estratégia didática que media a construção do conhecimento acadêmico e a necessidade do desenvolvimento das competências técnicas do professor para o trabalho online. PALAVRAS-CHAVE: Aprendizagem colaborativa. Docência online. Interatividade.

ABSTRACT: This paper aims to describe some results of a qualitative research article that sought to identify whether teachers who work in distance education using collaborative communication practices in the discussion forum as a teaching strategy in higher education online. The data collection technique was the focal group and the information gathered were interpreted in the method of content analysis. The data were analyzed by thematic analysis technique. The results showed that although teachers recognize that the EAD is an innovation that demand differentiated teaching approach and new relationships with knowledge, not even managed to distance himself completely from the exercise of pedagogy of transmission and implement the logic of linearity. The adaptation of the classroom environment for virtual scenery is still a strong aspect in the online mode. Respondents realize that collaboration is a teaching strategy that mediates the construction of academic knowledge. And the need to develop technical skills from teacher to work online.

KEYWORDS: Collaborative learning. Teaching online. Interactivity.

RESUMEN: Este trabajo tiene como objetivo describir algunos resultados de una pesquisa de investigación cualitativa que buscó identificar si los profesores que trabajan en la educación a distancia utilizando las prácticas de comunicación de colaboración en el foro de discusión como estrategia de enseñanza en la educación superior en línea. La técnica de recolección de datos fue el grupo focal y la información recopilada se interpretó en el método de análisis de contenido. Los datos fueron analizados mediante la técnica de análisis temático. Los resultados mostraron que aunque los profesores reconocen que el Educación a Distáncia - EAD es una innovación que exigen enfoque de la enseñanza diferenciada y nuevas relaciones con el conocimiento, ni siquiera logró distanciarse por completo del ejercicio de la pedagogía de la transmisión y aplicar la lógica de la linealidad. La adaptación del ambiente de la clase de escenografía virtual sigue siendo un aspecto fuerte en el modo online. Los encuestados se dan cuenta de que la colaboración es una estrategia de enseñanza que media la construcción del conocimiento académico y la necesidad de desarrollar habilidades técnicas de maestro a trabajar en línea.

PALABRAS CLAVE: Aprendizaje colaborativo. La enseñanza en línea. La interactividad.

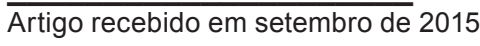

Aprovado em novembro de 2015

Cad. Pes., São Luís, v. 22, n. 3, set./dez. 2015 
COLABORAÇÃO COMO ESTRATÉGIA | Marta T. do Amaral Montes e Maria Judith S. da Costa Lins

\section{1 | INTRODUÇÃO}

Este artigo tem o objetivo de descrever alguns resultados de uma pesquisa qualitativa que visou identificar como docentes que atuam na educação a distância (EAD) coordenam as práticas comunicacionais no fórum de discussão e se utilizam a colaboração ou a aprendizagem colaborativa como instrumento didático no ensino superior online.

A discussão acerca da cibercultura e da educação online tem suporte teórico em Lévy (1999, 2008), Pallof e Pratt (2002, 2004), Santos (2005) e Morán (2015) e na teoria da tridimensionalidade de Verduim e Clark (1991). Para analisarmos e entendermos a importância da colaboração para a educação online, utilizaremos neste trabalho as definições de aprendizagem colaborativa dos seguintes autores: Stahl; Koschmann; Suthers (2006), Dillenbourg (1999) e Behrens (2012). No entanto, poderemos fazer menção a outros pesquisadores que também tratam do tema.

O conceito de aprendizagem colaborativa, embora pareça recente, já foi defendido por muitos estudiosos, ainda que, com outras terminologias. Definida como "uma situação em que duas ou mais pessoas aprendem ou tentam aprender algo em conjunto” (DILLENBOURG, 1999, p. 05), podemos vincular esta definição aos pressupostos de várias pedagogias, ao longo da história da Educação. As pedagogias de projetos ou progressistas disseminadas pela Escola Nova incluíam o conceito de aprendizagem colaborativa e se contrapunham ao modelo cartesiano de ensino, pois, compreendiam a aprendizagem como processo contínuo de formação global e holística em busca da criatividade, colaboração, exercício da cidadania e construção de sujeitos completos.

Podemos citar como exemplo Dewey. Ele entende que o indivíduo é um "ser vivo de funções ativas e especiais que se desenvolvem pela redireção e combinação em que entram quando se põem em contato ativo com o seu ambiente" (DEWEY, 1959, p. 77). Escola e sujeito têm natureza social sendo "forma de vida em comunidade" (DEWEY, 1959, p. 79). Concebe o sujeito de forma ativa e em interação permanente com o meio que o cerca, a fim de, modificá-lo e se adaptar a ele.

A aprendizagem colaborativa poderia, então, buscar os pressupostos teóricos nas tendências pedagógicas dos movimentos da Escola Nova ou nas propostas pedagógicas de Dewey, bem como na abordagem teórica do sociointeracionismo de Vigotski (1993) ou no Paradigma da Complexidade, a partir de uma "aliança entre a abordagem progressista de visão holística e o ensino com pesquisa” (BEHRENS, 1999) como componentes conjunturais de metodologias de ensino mais coesas às exigências contemporâneas.

Stahl; Koschmann; Suthers (2006) definem a aprendizagem colaborativa com suporte computacional como uma área das ciências da aprendizagem que estuda como as pessoas aprendem em grupo e mediadas por computador. Ainda afirmam que é um processo através do qual, indivíduos negociam e compartilham entendimentos relevantes à resolução do problema posto.

Dillenbourg (1999) afirma que o processo colaborativo pressupõe a realização conjunta do trabalho. A colaboração é uma "atividade coordenada resultado de uma tentativa contínua de construir e manter um entendimento compartilhado sobre um problema" (STAHL; KOSCHMANN; SUTHERS, 2006, p. 8).

Para Behrens (1999), a aprendizagem colaborativa se assenta sobre os quatro pilares destacados por Jacques Delors: aprender a conhecer, aprender a fazer, aprender a viver junto, aprender a ser e ressalta que, para uma prática colaborativa são necessárias algumas atitudes, como:

a) o aporte do paradigma emergente que associe os pressupostos da visão holística - superação da fragmentação do conhecimento; 
b) a abordagem progressista que visa à transformação social pelo diálogo;

c) o ensino com pesquisa onde professores e alunos produzam seus conhecimentos com criticidade.

Esses três aspectos devem ser associados à tecnologia inovadora, como um recurso para promover a aprendizagem colaborativa desses pilares (ALCÂNTARA et al., 2005).

Embora utilizem formas diferentes para conceituar a aprendizagem colaborativa, fica evidente que os autores concordam que é um processo de interação contínua e de construção conjunta e mútua entre os membros de um determinado grupo com o objetivo de buscar conhecimentos e competências.

Processos colaborativos são indispensáveis em diversas esferas sociais, exigindo do sujeito social sabedoria para transitar entre elas. A realidade social apresenta múltiplas provocações ao sujeito e à educação, igualmente, enormes desafios para o futuro, mas, sobretudo, é "condição necessária e indispensável à humanidade na construção de novos ideais, da liberdade e da construção social" (DELORS, 2010, p. 19).

Transpor o paradigma da linearidade, da simplificação e o pensamento disciplinar significa uma mudança epistemológica, social e pedagógica na forma de ensinar (MORÁN, 2015), de aprender e de viver. Acostumados à fragmentação das coisas e das ideias, precisamos agora mudar o ritmo, a direção e a orientação didática (LÉVY, 2008) para uma perspectiva complexa, rizomática e negociada (TARDIF, 2002) de educação. Eis aí um grande desafio!

A educação superior e suas demandas não se excluem do cenário colocado acima. Tampouco a educação online. Mesmo aparelhada pelo uso das tecnologias digitais não se exime das problemáticas tradicionais e históricas do processo de ensino e aprendizagem. Ao contrário, tem de lidar com todo o cenário educacional construído historicamente - há séculos - e ainda aditar a seu escopo as temáticas hodiernas oriundas da mediação tecnológica nos procedimentos educativos. Recursos e novidades tecnológicas não implicam, necessariamente inovações pedagógicas ou aumento qualitativo da aprendizagem (SANTOS, 2005). O que definirá esse aumento qualitativo será o investimento na formação humana e técnica do docente (PALLOF; PRATT, 2002; VERDUIM; CLARK, 1991) e em suas práticas educativas, na humanização das relações interpessoais e na perspectiva de um mundo complexo, relacional e conexo (MORÁN, 2015; BEHRENS, 2012; GADOTTI, 2000; PALLOF; PRATT, 2004).

A educação online (MORÁN, 2003) pressupõe uma mudança paradigmática e epistemológica do processo de aprendizagem e de ensino, uma vez que reconhece e altera os papéis sociais (BEHRENS, 2012) dos envolvidos e deles exige novos comportamentos, capacidade de comunicação, produção compartilhada, associação de ideias e conceitos, diálogo permanente (VERDUIM; CLARK, 1991; BEHRENS, 2012), reflexões éticas, corresponsabilidade no processo de aprendizagem. Redimensionou vários conceitos, como: o de distância, o de interatividade, o de aprendizagem, o de modelo comunicacional e o do trabalho docente. Assim sendo, pode ser definida como "o conjunto de ações de ensino e aprendizagem que são desenvolvidas através de meios telemáticos, como a Internet, a videoconferência e a teleconferência" (MORÁN, 2003, p. 40) que gerem, promovam e implementem situações de aprendizagem (LITWIN, 2001).

O modelo teórico de educação online proposto por Verduim e Clark (1991) está dividido em três dimensões: diálogo/suporte, estrutura/especialização e competência/autonomia. O diálogo pode variar de simples instruções até situações de aprendizado que envolvam o aluno emocionalmente mediante atividades que estão diretamente ligadas às situações reais e vivenciadas. A estrutura é indissociável da competência, pois resulta da experiência do aluno com os recursos tecnológicos. E autonomia é a capacidade de autoaprendizagem do sujeito. 
Na educação online as diversas atividades e as funções do docente são classificadas em quatro grandes áreas: pedagógica, social, gerencial e técnica (PALLOF; PRATT, 2002). A função pedagógica é a capacidade mediadora do professor entre o conteúdo e os alunos. A social refere-se à produção de um ambiente social agradável para a construção de uma comunidade virtual. A gerencial envolve regras referentes ao agendamento dos fóruns, do curso, o ritmo nas interações, os objetivos traçados, a elaboração de normas e a tomada de decisões. $E$ a técnica diz respeito à habilidade tecnológica do professor, sua familiaridade com os processos e as ferramentas do ambiente virtual. Quanto mais à vontade estiver o professor com a tecnologia utilizada, mais segurança passará ao seu aluno.

Algumas estratégias são importantes na educação online para a promoção da aprendizagem colaborativa e a manutenção da comunidade virtual (PALLOF; PRATT, 2004):

a) formulação de um objetivo comum para a aprendizagem;

b) exemplos da vida real;

c) estímulo ao questionamento inteligente na discussão;

d) divisão da responsabilidade pelos comentários;

e) avaliação entre os próprios alunos;

f) incentivo à escrita coletiva.

Esses procedimentos devem convergir para a construção de um ambiente que facilite a proposta da colaboração e da participação efetiva do grupo. Mas, precisam vir acompanhados de uma indicação teórico-metodológica (BEHRENS, 2012; MORÁN, 2015; PALLOF; PRATT, 2004; VERDUIM; CLARK, 1991) baseada na ação dialógica e no uso da tecnologia como suporte educativo (VERDUIM; CLARK, 1991). Pois, do contrário, todo o aparato tecnológico disponível no ambiente virtual de aprendizagem (AVA) será incapaz de proporcionar construção de conhecimento por mais midiático que seja o ambiente.

\section{2 | PROCEDIMENTOS METODOLÓGICOS}

O estudo de abordagem qualitativa se propôs inicialmente, a realização de pesquisa bibliográfica e exploratória acerca da aprendizagem colaborativa e das teorias da aprendizagem com objetivo de obter maior familiaridade com o problema, com vistas a explicitá-lo e a conseguir informações suficientes para as análises teóricas posteriores. $O$ enfoque qualitativo deve-se ao fato de considerarmos que existe uma relação dinâmica entre o mundo real pesquisado e o sujeito que o compõe. Este vínculo indissociável entre o mundo objetivo e a subjetividade do sujeito não pode ser traduzido em números (GIL, 2002), antes analisado sob o prisma das relações sociais.

Foi realizado um estudo de caso porque consideramos uma abordagem metodológica adequada, ao passo que nos conduz à compreensão, exploração e descrição de contextos complexos (YIN, 1994) para construção de conhecimentos acerca do fenômeno estudado. Igualmente comprova ou contrasta efeitos e relações presentes no caso (GUBA; LINCOLN, 1994), pretende avaliar a realidade com o objetivo de transformá-la (MERRIAM, 1998; GOMEZ; FLORES; JIMENEZ, 1996) e esclarecer os processos por meio dos quais as pessoas descrevem e explicam o mundo em que vivem (GERGEN, 1985). Uma perspectiva de que o conhecimento resulta das práticas sociais construídas conjuntamente e não de uma apreensão individual da realidade posta.

Como instrumento de coleta de dados foi utilizada a técnica do grupo focal. Essa técnica foi selecionada porque consideramos especialmente relevante a visão dos participantes em relação ao problema estudado e buscamos obter a compreensão dos entrevistados em relação ao tema. Os participantes narram, pormenorizadamente, suas experiências, o que pensam em relação aos comportamentos, as percepções e as atitudes, sob a coordenação de um moderador que lidera as atividades e os participantes. A seguir, descreveremos as etapas da aplicação dessa técnica: 
Foram convidados dez professores, no entanto apenas 6 compareceram. A atividade foi realizada com esse grupo de professores que ministram disciplinas no curso de graduação a distância de uma universidade particular no estado do Rio de Janeiro. Os objetivos da pesquisa eram:

a) investigar a avaliação desses docentes acerca da funcionalidade pedagógica do fórum de discussão para a construção de aprendizado colaborativo;

b) saber se os professores utilizam alguma base teórica para o planejamento e o desenvolvimento dos processos metodológicos e atividades no fórum de discussão;

c) averiguar a importância dada pelos professores aos processos de colaboração e se estes se constituíam para eles uma estratégia didática na construção do conhecimento acadêmico.

A pesquisadora atuou como facilitadora e ficou responsável pelo encaminhamento das perguntas, mediação dos comentários e condução da discussão do grupo. Uma câmera de vídeo ficou afixada em um ponto da sala e a atividade teve duração de 01h15min sendo inteiramente gravada por meio audiovisual, transcrita na íntegra e autorizada pelos participantes. Esse fato foi, antecipadamente, comunicado aos entrevistados, bem como, o direito do anonimato e o uso exclusivo das gravações para as finalidades da pesquisa. O objetivo da gravação foi o registro completo do conteúdo da discussão, sobretudo, dos comportamentos não verbais (expressões faciais, gestos). Os textos passaram por pequenas correções linguísticas, porém, não eliminando o caráter espontâneo das falas (BARDIN, 2002).

Bardin (2002) aponta algumas ações importantes para comporem as fases iniciais da pesquisa: a descrição ou preparação do material, a inferência ou dedução e a interpretação, sendo os principais pontos da pré-análise: a leitura flutuante (primeiras leituras de contato com os textos), a escolha dos documentos (no caso os relatos transcritos), a formulação das hipóteses e objetivos (relacionados com a disciplina), a referenciação dos índices e a elaboração dos indicadores (a frequência de aparecimento de determinados termos).

A discussão no grupo focal iniciou-se com temas de caráter geral para facilitar a abordagem e a participação imediata dos integrantes. Em seguida, foram propostas as questões mais específicas e de caráter analítico no que tange à docência online. A seguir está descrita a íntegra do roteiro utilizado na atividade:

Questão A (de caráter geral) - Como você percebe a educação no Brasil e a educação online.

1. Questão-chave 1: O que é ser professor online?

a) Mediação e coordenação das atividades realizadas; b) Funcionalidade da plataforma utilizada; c) Dificuldades encontradas; d) Ações para a superação das dificuldades; e) Base teórica utilizada como sustentação.

2. Questão-chave 2: Como é a educação através da modalidade online?

a) Como é realizada a comunicação entre aluno-professor, aluno-aluno?; b) A comunicação realizada pelos canais disponíveis na plataforma é eficaz para produzir conhecimento acerca dos conteúdos estudados?; c) como é realizada a construção de aprendizado pelo aluno?; d) O aluno alcança os objetivos propostos para a disciplina?

3. Questão-chave 3: Como é feita a interatividade em um curso à distância online?

a) Há uma estratégia metodológica utilizada?; b) Promove uma dinâmica diferente daquela realizada na sala de aula presencial?; c) Promove conhecimento?; d) Pode ser vista como uma estratégia didática?

As informações coletadas constituíram o corpus do estudo e os dados originários da atividade do grupo focal foram interpretados utilizando-se o método da "análise de conteúdo" (BARDIN, 2002) que objetiva desvendar as significações de diferentes tipos de discursos baseando-se na inferência para a criação de categorias de análise. Esse método é muito utilizado na análise de dados qualitativos e compreende um conjunto de técnicas de pesquisa cujo objetivo é a busca do sentido ou dos sentidos de um documento ou arquivo. 
Em seguida, utilizamos a técnica da análise temática ou categorial para interpretar os dados coletados, que de acordo com Bardin (2002), fundamenta-se em operações de desmembramento do texto em unidades menores para descobrir os diferentes núcleos de sentido que constituem a comunicação, e, posteriormente, o reagrupamento em classes ou categorias.

Dessa maneira, foram selecionadas, a priori, as seguintes categorias de análise para essa etapa: mediação, funcionalidade da plataforma, dificuldades encontradas no fórum de discussão e possíveis soluções, comunicação, eficácia dos canais de comunicação, construção do conhecimento, colaboração, processos metodológicos e interatividade como estratégia didática. Essas categorias apresentam-se nas seguintes temáticas:

a) a mediação docente no AVA;

b) dificuldades encontradas pelos docentes para estabelecer a colaboração no fórum;

c) ações para superação das dificuldades;

d) planejamento de atividades para o fórum de discussão visando superar os desafios da interatividade;

e) processos metodológicos para a docência online;

f) competências necessárias para a docência online.

As fases que se seguiram a esta foram a de exploração do material quando foi feita a codificação do conteúdo das entrevistas em recortes de unidades de contexto e de registro ${ }^{1}$ (BARDIN, 2002) e a fase da categorização quando os requisitos básicos foram a exclusão mútua, homogeneidade, pertinência, objetividade, fidelidade e produtividade.

Finalmente, a última fase do tratamento foi a inferência, ou seja, a interpretação dos dados recoIhidos. Esse procedimento permite que o conteúdo pesquisado se constitua "em dados quantitativos e/ou análises reflexivas em observações individuais e gerais das entrevistas" (BARDIN, 2002, p. 78).

Toda a metodologia da pesquisa foi desenvolvida e interpretada à luz do referencial teórico adotado para a pesquisa de Dissertação - aqui um recorte, com o intuito de relacionar os dados coletados ao quadro teórico utilizado para a discussão acadêmica do problema. Todos os dados coletados com professores serviram de base para a análise sobre a colaboração e do modelo comunicacional no fórum de discussão, visando analisar as categorias da colaboração e da construção do conhecimento coletivo a partir da interação nesse ambiente.

Estabelecemos como procedimentos para maximizar a confiabilidade dos dados: a permanência prolongada no campo para que as observações específicas fossem feitas por repetidas vezes e o questionamento por pares, solicitando a alguns outros professores que trabalham com graduação a distância que analisassem as interpretações dos dados feitas pela pesquisadora.

\section{3 | INTERPRETAÇÃO DOS RESULTADOS DA PESQUISA}

Para oferecer maior entendimento aos leitores sobre como foi realizada a pesquisa, reiteramos que no item anterior expusemos a íntegra do processo metodológico utilizado neste trabalho, descrevendo todas as categorias e temáticas construídas a priori e no processo hermenêutico dos dados coletados. No entanto, neste item será exposto somente parte dos resultados da pesquisa principal, referentes a duas questões de estudo propostas na Dissertação.

A primeira questão-chave fazia a seguinte pergunta: O que é ser professor online? Após lançarmos essa pergunta, inseríamos alguns temas correlatos, no decorrer da conversa, para serem co-

\footnotetext{
${ }^{1}$ De acordo com Bardin (2002), unidade de registro (UR), apesar de dimensão variável, é o menor recorte de ordem semântica que se liberta do texto, podendo ser uma palavra-chave, um tema, objetos, personagens, etc. Já unidade de contexto (UC), em síntese, deve fazer compreender a unidade de registro, tal qual a frase para a palavra.
} 
mentados pelos professores. Isso nos ajudou na fase de exploração do material quando fizemos os recortes nos textos e retiramos as categorias que serão exibidas a seguir.

A categoria inicial refere-se à "mediação e a coordenação das atividades realizadas no fórum de discussão". Neste item, as respostas dos professores divergiram no que tange, ao modelo pedagógico e de educação. Indicaram dois polos opostos. De um lado, as respostas de alguns professores expuseram, claramente, a prática da pedagogia da transmissão e da transposição do ambiente presencial para o cenário virtual: "[...] na mediação a gente tira as dúvidas do aluno, busca auxiliar o aluno para que ele vá para o caminho correto que é apreender". Essa afirmativa expõe o comportamento passivo e receptivo do docente, à medida que ele acredita que mediação é somente atender a uma solicitação de esclarecimento de dúvidas. Por isso seu comportamento é o de esperar por um pedido do aluno. Caso não haja dúvida, não há interação.

A mediação pedagógica busca abrir caminhos e novas relações com o educando (VERDUIM; CLARK, 1991), a aprendizagem, os conteúdos, as áreas do conhecimento, os contextos (PALLOF; PRATT, 2004) e, especialmente, com os outros sujeitos envolvidos no processo (SANTOS, 2005; PEREZ; CASTILLO, 1999; LÉVY, 1999, 2008). Tem como características o diálogo permanente, as trocas de experiências, os debates a partir das dúvidas levantadas, as problematizações, a orientação sobre conteúdo e dificuldades técnicas que o aluno tenha e, sobretudo, o intercâmbio entre aprendizagem e sociedade (MORÁN; MASETTO; BEHRENS, 2012).

O professor desnuda-se da roupagem histórica da transmissão de informações para vestir-se de orientador do aluno, consultor de trabalho, com o objetivo de dinamizar a aprendizagem do grupo. Essa perspectiva vê a educação como um meio propício à ação do sujeito-educando em um ambiente problematizador, complexo e interrelacional.

De outro lado, ainda nesta categoria, outro professor manifesta, que mediar o conhecimento no fórum de discussão, é tecer uma série de novas tarefas, tanto para o aluno quanto para o professor (SANTOS, 2005; PALLOF; PRATT, 2004; MORÁN, 2015). Na fala deste professor percebemos ora nuances tradicionais ora progressistas, como se ainda não tivesse entendido bem o processo de ensinar e aprender na modalidade online:

[...] em prática continuamos desenvolvendo o processo tradicional de comunicar conhecimento (faz gesto de doar com as mãos), porém, o ensino online exige de certa maneira que esse trabalho de coordenação do conhecimento seja cada vez mais distribuído entre alunos e professores [...]

Este fragmento aponta para a discussão do processo ensino e aprendizagem e assinala os conceitos de ensinar e de aprender. Enquanto o primeiro (ensinar) está diretamente ligado ao professor que, mediante suas ações, facilita a construção dos conhecimentos pelos alunos, o segundo está associado com o aluno, sujeito do processo de aprendizagem que deve buscar e adquirir conhecimento, ressignificar os conteúdos, produzir reflexões, pesquisar, dialogar, "debater, desenvolver competências pessoais e profissionais, atitudes éticas, políticas, integrar conceitos [...]" (MORÁN; MASETTO; BEHRENS, 2012, p. 139).

Como visto no primeiro depoimento, parece-nos que aquele professor ainda é cativo da antiga prática docente que valoriza o conteúdo e o ensinamento como fatores basilares no processo educativo. Privilegiando a técnica da transmissão para transferência de informações. As atividades do fórum, sob está ótica, passam a ser apenas obrigação da disciplina, réplicas dos exercícios feitos na sala de aula presencial sem qualquer interferência no desenvolvimento integral do aluno: "espírito e corpo, inteligência, sensibilidade, sentido estético, responsabilidade pessoal, espiritualidade" (DELORS, 2010, p. 99.). Tampouco, ajuda o aluno na elaboração de pensamentos autônomos ou na formulação de seus próprios juízos de valor ou tomada de decisão em sua vida social (DELORS, 2010). 
Podemos, ainda, ressaltar a importância da utilização do esquema comunicacional todos-todos (SILVA; CLARO, 2007), da colaboração e da interdisciplinaridade como estratégias didáticas na orientação do trabalho do aluno num AVA. Esse esquema coaduna-se com o papel social da universidade descrito pelo Plano Nacional da Graduação (PNG), quando ressalta que esta instituição social deve transversalizar seus conteúdos pela vertente humanística, sobretudo, pela ética concernente à amplitude da existência humana, uma vez que, "as exigências sociais atuais determinam uma formação profissional universitária ampla e plena que articule a competência científica com técnica, com a inserção política e a postura ética" (FÓRUM NACIONAL DE PRÓ-REITORES DE GRADUAÇÃO DAS UNIVERSIDADES BRASILEIRAS, 1999, p. 8).

Não obstante, as falas de outros docentes conotaram a possibilidade de um trabalho pedagógico diferenciado na modalidade online porque este exige uma mudança no processo de aprendizagem (SANTOS, 2005; PALLOF; PRATT, 2004; MORÁN, 2015; BEHRENS, 2012), bem como um comportamento mais ativo tanto para professor quanto para aluno.

Eu sempre penso que a mediação precisa ter um conteúdo de orientação para que esse processo tenha consistência teórico-prática. Mediando o que? O professor deve se colocar numa situação de empatia porque ele está ali para orientar, para mediar, por isso que eu digo orientar porque tem que assumir um papel de educador [...]

"Assumir um papel de educador" evoca o conceito de participação e apresenta o aluno como protagonista do processo de ensino abrindo espaço para a aprendizagem colaborativa e todas as suas consequências pedagógicas baseadas no diálogo, na pesquisa, na colaboração e na relação com os outros e com o mundo.

O professor online antes de tudo é aquele que consegue transcender do diálogo presencial para o diálogo imaginário porque o aluno online não está agregado por espaço geográfico, como polo ou campus de uma universidade; não está agregado por idade ou por origem, por cultura por nenhum dos elementos que percebemos na sala de aula presencial.

A mediação tecnológica na educação impõe desafios à prática docente atual, como exposto no depoimento anterior. $O$ trabalho do professor precisa adornar-se de uma ação pedagógica que conduza à produção do conhecimento e à construção de um sujeito reflexivo e inovador independente do espaço geográfico, da idade ou da origem desse indivíduo. O vínculo que une o grupo é a interação, a colaboração e a vontade de estar no AVA.

Um aspecto marcante nessa categoria é a identificação de a maioria dos professores entrevistados ainda compreenderem a mediação como um processo unilateral e individual: "[...] na aula online isso não se dá, a interação é individual". Ainda sobre este aspecto outro professor comenta:

Eu falei com o Douglas, mandei uma mensagem para ele. Enviei uma mensagem diferenciada para a Ingrid porque vejo que está precisando de algo a mais. Então essa comunicação individualizada é um ganho na EAD.

Os depoimentos mostram uma discrepância entre o que se propõe para processos de mediação utilizando as tecnologias digitais e as falas dos professores na categoria mediação. Enquanto defendemos que não se pode educar para a vida sem uma educação colaborativa e participativa (PEREZ; CASTILLO, 1999), compreendemos nas falas dos professores, na sua maioria, que a educação a distância (EAD) tem sido feita de maneira unilateral, solitária e dentro da perspectiva da transmissão, abrindo espaço para mais um modelo comunicacional: o de um-um. Talvez esteja aí uma das dificuldades de mantermos os alunos no AVA porque eles vivenciam espaços digitais 
onde todos se comunicam com todos, como por exemplo: o Facebook ou os grupos de Whats app.

As novas tecnologias interativas romperam com o paradigma tradicional moderno, com a linearidade da transmissão das informações e com modelo comunicacional unidirecional. Entretanto, percebemos que muito ainda temos que aprender no tocante à EAD, pois a prática docente nesta modalidade ainda está pautada na fragmentação clássica da emissão/professor $\mathrm{X}$ recepção/ alunos (SILVA, 2001).

O uso do computador e da internet na educação criou possibilidades diferentes daquelas conhecidas na metodologia da sala de aula presencial e propiciou a abertura para novas descobertas educativas no que tradicionalmente era considerado como Educação a Distância (PALLOF; PRATT, 2002). A aprendizagem online necessita de abordagem diferenciada e de sujeitos participativos, por isso sua referência é a prática pedagógica ancorada no paradigma emergente. $E$ se caracterizará por três enfoques interdependentes: o ensino com pesquisa, a abordagem progressista e a visão holística ou sistêmica (BEHRENS, 2012).

O ensino como pesquisa rompe com o paradigma da transmissão do conhecimento porque busca a produção realizada pelo aluno e com o aluno, a partir de um processo investigativo. A abordagem progressista entende que a "transformação social" (BEHRENS, 2012) é elemento fundamental no processo de aprendizagem, por isso incentiva a discussão coletiva, a aprendizagem significativa (AUSUBEL, 1980), os trabalhos colaborativos, as parcerias e a ação-reflexão de alunos e professores. E, finalmente, a visão holística resgata o conceito de totalidade, tentando superar a fragmentação do conhecimento e intencionando a formação de um sujeito humano, ético e sensível a partir da consideração de suas múltiplas inteligências (BEHRENS, 2012).

A colaboração pressupõe uma metodologia de produção do conhecimento na universidade que estimule a autonomia do aluno, sua criatividade e, sobretudo, utilize a investigação como instrumento didático na construção e produção do conhecimento (VERDUIM; CLARK, 1991). Para que esta perspectiva metodológica se efetive é necessária a proposição de uma ação pedagógica que incite o estudo sistemático e a investigação orientada com a finalidade de impulsionar o aluno aprender a aprender (MORÁN, 2015; BEHRENS, 2012; VERDUIM; CLARK, 1991). Ou seja, a educação do século XXI precisa convergir em direção a um conceito amplo de educação: o de "sociedade educativa", onde todos os espaços oportunizam o aprendizado e o desenvolvimento de talentos (DELORS, 2010, p. 32).

Ainda no quesito colaboração, os professores assinalaram a importância da capacitação para o trabalho de docência online:

[...] eu melhorei muito o atendimento depois que eu fui aluna online. Aí você consegue entender quais são as dificuldades que seu aluno está passando. É você se colocar no lugar do outro e entender quais são as dificuldades e o que levou ele fazer a disciplina online para facilitar o trabalho. Quando digo facilitar o trabalho não é aprovar qualquer um, mas fazer com que a aprendizagem seja suave...ou seja, uma coisa menos pesada. Os cursos (de capacitação) facilitaram muito porque a gente aprende a lidar com as ferramentas. Mas você só aprende a lidar com o aluno, lidando.

O trecho acima aponta dois pontos importantes: as funções sociais e técnicas do professor, na docência online. É importante que o professor crie no seu fórum de discussão um ambiente social amigável e agradável para manter a coesão e a participação do grupo. Também é um aspecto imprescindível à aprendizagem online. O professor deve estimular as relações humanas com o reconhecimento da contribuição de cada aluno e incentivos para a união do grupo. Esses elementos promovem colaboração sendo essenciais para a construção e a sustentação de uma comunidade virtual e para que "os participantes trabalhem juntos por uma causa comum" (BEHRENS, 2012, p. 104). 
A função técnica refere-se à habilidade tecnológica do professor, sua familiaridade com os processos e as ferramentas do ambiente virtual utilizado. Num AVA a tecnologia precisa ser clara e transparente (CLEMENTINO, 2008) tanto para professor quanto para aluno. Quanto mais à vontade estiver o professor com a tecnologia utilizada, mais segurança passará ao seu aluno. Também, importante ressaltar que o professor de um curso deve "acreditar na modalidade de EAD para o processo de ensino e aprendizagem" (CLEMENTINO, 2008, p. 92), compartilhar de seus pressupostos e compreender e assumir a sua função social de "sujeito comunicante" no contexto do curso (PENTEADO, 2002). A função pedagógica é a capacidade mediadora do professor entre o conteúdo e os alunos e uma estratégia didática que promove a permanência do aluno no fórum.

A segunda questão-chave fazia o seguinte questionamento: Como é a educação através da modalidade online? Desta pergunta derivaram-se várias categorias. A primeira delas é a comunicação. Nesta categoria houve divergências de pensamento entre os professores. Enquanto uns afirmaram que a comunicação é plena e potencializa a aprendizagem na modalidade online, outros discordaram, veementemente, assegurando que a comunicação virtual é frágil e necessita de incrementos.

A comunicação "entre aluno e professor é boa; entre aluno e aluno é fraca". Essa afirmação aponta a falta de interatividade na plataforma e o fórum como um espaço apenas para postagem de tarefas solicitadas pelo professor como complemento de nota da prova. Não há interação entre os alunos de forma a criar um ambiente colaborativo.

\begin{abstract}
O modelo de nossa instituição é extraordinário porque os professores online trabalham juntos no mesmo ambiente físico. Isso facilita as trocas entre os professores, mas acho que falta uma interdisciplinaridade maior. Acho que a gente já tem hoje as pré-condições: os professores se encontram, o que não acontece no dia-a-dia [...] Mas não conseguimos ainda delimitar um espaço de troca, estamos separados em janelas distintas e não trabalhando todos conjuntamente fazendo a interdisciplinaridade verdadeira, quer dizer vários professores numa mesma sala de aula com os mesmos alunos.
\end{abstract}

Percebemos nas falas desses professores que, embora estejam atuando na EAD e na modalidade online, continuam perfazendo suas práticas docentes baseadas no modelo comunicacional tradicional, esquema um-todos: "a aula está ali como mediação entre o professor e o aluno. Nossa comunicação é feita através do suporte que temos no fórum e nas teletransmissões". Não identificamos ligação afetiva ou cognitiva do professor com o desenvolvimento de seu aluno, pois ele delega à leitura individual feita pelo educando a mediação do processo de aprendizagem, invalidando as diversas possibilidades criadas pela cibercultura e ignorando as atividades de sua docência na educação online: "pedagógica, social, gerencial e técnica" (PALLOF; PRATT, 2002, p. 82).

Esta afirmação se confirma: (1) nos exemplos de atividades propostas para os fóruns de discussão que retiramos de disciplinas da graduação e (2) nos depoimentos dos professores, como o que segue:

O conhecimento da online é meio que reproduzindo aquela verdade do presencial. Se deveria ter menos conteúdo e mais indicações de busca de conteúdo. Deixar de entregar o conteúdo já pré-formatado e entregar ele na direção de onde a gente pode ir buscar ou pesquisar.

O depoimento acima assinala questões importantes acerca das novas competências do professor online: produção de conteúdo, construção de conhecimento, pesquisa, busca e interação. No entanto, a percepção de educação contida nessa declaração é a bancária, a da "entrega do conteúdo" (FREIRE, 1983). Essa visão dificulta o processo colaborativo porque: (1) ainda se acredita que a educação se faz de 'a' para 'b' e (2) remete-nos, novamente, à prática comunicativa tradicional no qual a fala (ou escrita, neste caso) é unidirecional e informativa, visando apenas a uma única reação do interlocutor: a retenção passiva da informação prestada. 
Ainda, nessa questão da colaboração perguntamos aos professores até que ponto empregam a colaboração ou a interação como estratégia didática na construção do conhecimento acadêmico? Constatamos que esse ainda é um ponto preocupante na docência online, porque a grande maioria dos professores entrevistados ainda utilizam a pedagogia da linearidade, o que inviabiliza a colaboração e a interação nas discussões nos fóruns: "acho que a mediação funciona muito bem, nosso único 'calo' ainda é buscar o aluno para dentro de sala de aula, ou seja, conseguir que ele abra o sistema. É o grande problema que eu vejo."

Ora, ao lermos esse depoimento, logo nos perguntamos: como a mediação pedagógica funciona bem se não há a presença de alunos? A simples transposição do esquema presencial de docência não se aplica ao ambiente digital. Como vimos discutindo ao longo deste trabalho, é necessária uma nova abordagem que passa, necessariamente, pela pesquisa, pela autonomia discente, pela interação contínua e pela visão progressista.

[...] educar significa que algo que eu diga você precisa me devolver positiva ou negativamente da melhor maneira possível. Eu quero um efeito [...] isso ocorre em uma sala de aula ou em uma família porque nesse momento vai à falência o princípio da transmissão do conhecimento e entra o da modificação do conhecimento.

Por isso, importante destacar a importância do redimensionamento de conceitos na educação online, da postura didática do professor e das estratégias metodológicas com a finalidade da construção de um ambiente que facilite a proposta da colaboração e a participação efetiva do grupo. Essas propostas devem estar abalizadas nos princípios da interatividade e nos pressupostos da aprendizagem colaborativa.

Essa indicação teórico-metodológica está baseada na ação dialógica, na práxis docente (FREIRE, 1983) e no uso da tecnologia como suporte educativo. Essa tríade pode se tornar uma nova ação educadora onde "professor e alunos participem de um processo conjunto para aprender de forma criativa, dinâmica, encorajadora que tenha como essência o diálogo e a descoberta" (BEHRENS, 2012, p. 77). Porque nenhuma ferramenta tecnológica disponível no AVA será capaz de proporcionar mudanças significativas no desenvolvimento integral do aluno e o ambiente passará a ser visto apenas como a transposição da sala de aula presencial.

\section{4 | CONSIDERAÇÕES FINAIS}

Percebemos que, embora o professor online reconheça que a EAD se constitui em uma nova modalidade de ensino e que institui novos comportamentos tanto para alunos como para professores, ele ainda não conseguiu romper, totalmente, com a pedagogia da linearidade, típica do paradigma cartesiano. A atitude mais comum realizada pelos professores-tutores é a da transposição da didática bancária (FREIRE, 1996) da sala de aula presencial para o AVA. Identificamos poucas práticas colaborativas no fórum que fossem adaptações do ambiente presencial. E sabemos que na sala de aula presencial temos muitas oportunidades de realizar trabalhos interativos, colaborativos e de relação dialógica entre os alunos e professores.

Entendemos, portanto, que a concepção educacional para a construção de uma educação autêntica não se faz de “'a' para' b', nem de 'a' sobre 'b', mas, de 'a' com 'b' (FREIRE, 1996, p. 84). Por isso tão importante nossa reflexão, enquanto professores, sobre as novas competências que devemos desenvolver para a atuação como docentes online. Especialmente, a construção de uma pedagogia que abarque a pesquisa, a visão holística e a abordagem progressista dentro da perspectiva colaborativa que seja elemento fundamental e estratégico para a ocorrência da 
aprendizagem. A colaboração acontece por meio das potencialidades técnicas de determinado meio e, sobretudo, pela ação humana sobre esse meio com a finalidade de modificá-lo.

O professor precisa conferir sentido ao conteúdo (AUSUBEL, 1980) do ambiente e estabelecer uma relação negociada (TARDIF, 2002) com o grupo para promover interesse e participação (PALLOF; PRATT, 2002). Em contrapartida, o aluno deve ser um pesquisador e produtor de conhecimento a partir das orientações docentes.

Outro fator importante, neste sentido, é o do paradigma comunicacional. Necessário se faz que consigamos nos desprender do esquema "um-todos" para o "todos-todos" (SILVA; CLARO, 2007). Essa didática participativa promoverá uma nova pedagogia que conduzirá a colaboração do grupo nas atividades propostas e a interdisciplinaridade como estratégias didáticas na orientação do aluno no AVA. E, por conseguinte, a construção do conhecimento por cada um dos participantes.

Ora, se os alunos no ambiente online não estão agregados por nenhum dos elementos do contexto presencial é lógico pensarmos que as técnicas daquele ambiente também não são razoáveis para a modalidade a distância. A necessidade de transcender pode significar a busca por subsídios pedagógicos diferenciados para a EAD (VERDUIM; CLARK, 1991).

Como afirmamos anteriormente, o esquema todos-todos desloca os pilares da pedagogia da transmissão e promove uma pedagogia inovadora porque concebe o conhecimento como algo provisório e relativo (BEHRENS, 2012). Dessa maneira, professor e aluno são sujeitos de suas ações e não mais objetos de um conhecimento reproduzido.

O planejamento das atividades para o fórum de discussão deve, portanto, considerar esses aspectos (SANTOS, 2005; PALLOF; PRATT, 2002) e oportunizar a multidirecionalidade em rede dentro da perspectiva da dinâmica da emissão e recepção como polos complementares e criativos, pois, do contrário, subutilizaremos as potencialidades comunicacionais da web e do AVA.

Quanto à questão da colaboração como estratégia didática na construção do conhecimento acadêmico, vimos que esse ainda é um ponto crítico na docência online, porque, mesmo sabendo que a colaboração ou a interação é condição fundamental para que a aprendizagem ocorra (PETERS, 2003), muitos professores ainda utilizam a pedagogia da linearidade, o que inviabiliza a colaboração e a real interatividade nas discussões nos fóruns.

A simples transposição do esquema presencial de docência não se aplica ao ambiente digital e o modelo de transmissão dos conteúdos prontos, acabados e lineares não dá conta do universo de conhecimento inaugurado pela internet e pela educação online (PALLOF; PRATT, 2002; PETERS, 2003; MORÁN, 2015).

Assinalamos, para futuras discussões, a importância da associação entre as Teorias da Aprendizagem e a Tecnologia para o desenvolvimento de interfaces diferenciadas, colaborativas e compatíveis às peculiaridades de cada disciplina. Para que isso ocorra, é necessário que se coadune os aportes teóricos destas áreas para a composição de um AVA que proporcione interfaces funcionais de modo a atender:

a) as exigências educativas das diferentes disciplinas;

b) as necessidades atuais dos alunos;

c) promover processos dinâmicos e colaborativos (VERDUIM; CLARK, 1991; SANTOS, 2005; MORÁN, 2015; BEHRENS, 2012; LÉVY, 1993).

Concluímos que os processos comunicacionais no fórum podem ser aperfeiçoados com a mediação docente baseada na tríade ensino com pesquisa, abordagem progressista e visão holística (BEHRENS, 2012). Mas, se faz necessário um movimento do professor em busca de atualização com: os princípios da cibercultura (LÉVY, 1999) e com as pedagogias que atuem dentro do paradigma da complexidade (MORÁN, 2015) e que concebem a educação como uma atividade reflexiva, como uma prática social enriquecida pela natureza ética da Educação (LINS, 2010). 
Nesse sentido, observamos a necessidade de que os planejamentos didáticos para a docência online se preocupem com os aspectos atitudinais do aluno, à medida que ele é um ser social que pensa, sente, duvida, levanta hipóteses e elabora a vida no contexto da realidade complexa, dinâmica e indeterminada. As metodologias didáticas utilizadas devem eleger uma abordagem progressista para construir uma pedagogia que visualize o ambiente digital como meio para que a educação se processe através de seus protagonistas: alunos e professores.

Destacamos como contribuições eficientes para a educação online, a aprendizagem colaborativa mediante a proposição de projetos em grupo. Ambas se constituem em subsídios basais para ações pedagógicas desafiadoras coerentes com as exigências do mundo contemporâneo, pois as necessidades hodiernas determinam a formação de pessoas e profissionais que acompanhem a evolução do conhecimento e assumam a vida social de forma consciente, crítica e participativa, manifestando características apropriadas à participação social, ao compromisso político e à cidadania (MORÁN, 2003).

Ser aluno, na era das redes sociais, é conceber e entender o mundo através da interação e da colaboração representada na evolução frenética das tecnologias digitais e na expansão da realidade no ciberespaço (VERDUIM; CLARK, 1991).

Por isso, a prática pedagógica contemporânea deve romper com os limites redutores (SANTOS, 2005) e lineares da educação tradicional e conectar-se a uma ação didática complexa e interativa para alargar o desenvolvimento intelectual e acadêmico dos aprendizes. Outrossim, propiciar que as discussões nos fóruns consistam em proveitosos momentos na vida acadêmica do aluno e contribuam para o amadurecimento intelectual e ético do grupo numa perspectiva dialógica (GADOTTI, 2000) de construção de conhecimento significativo.

Nesse sentido, as evidências da pesquisa apontaram para uma indispensável mudança atitudinal no que tange ao cenário educativo online (VERDUIM; CLARK, 1991; PETERS, 2003). Professores e alunos precisam deixar seus postos de emissor e receptor de mensagens educativas, respectivamente. O comportamento dos sujeitos deve ser encaminhado para a atitude da colaboração pois todo conhecimento é construído socialmente antes de ser internalizado pelo indivíduo e esse processo de interiorização acontece - no fórum de discussão - mediado pela linguagem e pela ação docente. Daí sua importância como elemento pedagógico para a construção e a formação de sujeitos que compreendam a realidade social em que vivem e que respondam satisfatoriamente às inúmeras provocações e desafios do cotidiano.

Transpor o paradigma da linearidade, o pensamento disciplinar significa uma mudança epistemológica, social e pedagógica na forma de ensinar, de aprender e de viver. O grande desafio didático se coloca na mudança do olhar e do planejamento fragmentados para a orientação didática complexa e negociada de educação (TARDIF, 2002).

O AVA é um universo de possibilidades que se esquematiza no modelo digital, a partir da exploração de seus interagentes que o alimentam constantemente. Quando as interações modificam o modelo, o mundo digital torna-se "um vetor de inteligência e criação coletivas" (LÉVY, 1999, p. 75), à medida que a inteligência coletiva (LÉVY, 1999) é uma inteligência de liberdade, de não totalitarismo, que valoriza cada ser humano e compreende em si os saberes de todos, em busca de uma aproximação do saber absoluto.

A educação online precisa centrar-se no reconhecimento do sujeito social (BEHRENS, 2012), na importância do outro e dos processos coletivos (LÉVY, 1999) para a construção do saber. Sobretudo, na criação e manutenção de ambientes de aprendizagem (LITWIN, 2001) que favoreçam a interdisciplinaridade, a transversalidade (LEWGOY; ARRUDA, 2003), a mediação e a colaboração. 


\section{Referências}

ALCÂNTARA, P. R. et al. A aprendizagem colaborativa na educação a distância on-line. Paraná: PUC, 2005. Disponível em: <http://www.abed.org.br/congresso2005/por/pdf/171tcc3.pdf>. Acesso em: 20 abr. 2011.

AUSUBEL, D. P. Psicologia Educacional. Rio de Janeiro: Interamericano, 1980.

BARDIN, L. Análise de conteúdo. São Paulo: 70, 2002.

BEHRENS, M. A. Projetos de aprendizagem colaborativa num paradigma emergente. In: CLEMENTINO, A. Didática intercomunicativa em cursos online colaborativos. Tese apresentada à Faculdade de Educação, Universidade de São Paulo - USP, 2008. Disponível em: <http://www.teses.usp.br/teses/disponiveis/48/48134/ tde-12062008-131412/pt-br.php>. Acesso em: 29 de março de 2012.

BEHRENS, M. A. A prática pedagógica e o desafio do paradigma emergente. Revista Brasileira de Estudos Pedagógicos, Brasília, v. 80, n. 196, p. 383-403, set./ dez. 1999.

DELORS, J. (Org.). Educação: um tesouro a descobrir: relatório para a Unesco da Comissão Internacional sobre Educação para o século XXI. 4. ed. Tradução Guilherme João de Freitas Teixeira. Brasília: UNESCO, 2010.

DEWEY, J. Democracia e educação. Tradução Godofredo Rangel e Anísio Teixeira. 3. ed. São Paulo: Nacional, 1959. Disponível em: <http://www.scielo.br/ scielo.php?script=sci_nlinks\&ref=000120\&pid=S1413$7372200200010000800011 \&$ Ing=en>. Acesso em: 2 fev. 2012.

DILLENBOURG, P. Introduction: what do you mean by «collaborative learning»?. In: (Ed.). Collaborative learning: cognitive and computational approaches. Amsterdam: Pergamon, 1999. Disponível em: <http:// tecfa.unige.ch/tecfa/publicat/dil-papers-2/Dil.7.1.14.pdf>. Acesso em: 15 maio 2011.

FREIRE. P. Pedagogia da autonomia: saberes necessários à prática educativa. São Paulo: Paz e Terra, 1996.

Pedagogia do oprimido. 12. ed. Rio de Janeiro: Paz e Terra, 1983.

GERGEN, K. J. The social constructionist movement in modern psychology. American Psychologist, v. 40, n. 3, p. 266-275, 1985.

GIL, A. C. Como elaborar projetos de pesquisa. 4. ed. São Paulo: Atlas, 2002.
GUBA, E. G.; LINCOLN, Y. S. Competing paradigms in qualitative research. In: DENZIN, N. K.; LINCOLN, Y. S. (Ed.). Handbook of qualitative research. Thousand Oaks, CA: SAGE Publications, 1994. p. 105-117.

GADOTTI, M. Perspectivas atuais da educação. São Paulo em Perspectiva, São Paulo, v. 14, n. 2, abr./jun. 2000 . Disponível em: <http:// www.scielo.br/scielo.php?script=sci_arttext\&pid=S0102-88392000000200002\&lng=en\&nrm=iso>. Acesso em: 01 out. 2011.

GOMEZ, G. R.; FLORES, J.; JIMÈNEZ, E. Metodologia de la investigacion cualitativa. Malaga: Aljibe, 1996.

LÉVY, P. Beyond semantic web: semantic space. WKD Conference. Canada: University of Ottawa. Sept. 2008. Disponível em: <https://drive.google.com/folderview?ddrp=1\&id=0B-YLV8egGwSuUm9yRIdCbWgzbVU\#>. Acesso em: 25 mar. 2012.

Cibercultura. Tradução Carlos Irineu da Costa. São Paulo: 34, 1999.

As tecnologias da inteligência: o futuro do pensamento da era da informática. São Paulo: 34, 1993.

LEWGOY, A. M. B.; ARRUDA, M. P. de. Da escrita linear à escrita digital: atravessamentos profissionais. Revista Virtual Textos \& Contextos, ano 2, n. 2, dez. 2003. Disponível em: <http://revistaseletronicas.pucrs. br/ojs/index.php/fass/article/view/955/735>. Acesso em: 23 abr. 2012.

LINS, M. J. S. C. Ética e formação de professores. In: CONGRESSO INTERNACIONAL DE FILOSOFIA E EDUCAÇÃO, 5., 2010, Caxias do Sul. Anais... Caxias do Sul: UCS, 2010.

LITWIN, E. Das tradições à virtualidade. In: (Org.). Educação a Distância: temas para o debate de uma nova agenda educativa. Porto Alegre: Artmed, 2001.

MERRIAM, S. Qualitative research and case studies applications in education: revised and expanded from case study research in education. San Francisco: Jossey-Bass, 1998.

MORÁN, J. M. Mudando a educação com metodologias ativas. In: SOUZA, C. A. de; MORALES, O. E. T. (Org.). Convergências midiáticas, educação e cidadania: aproximações jovens. Ponta Grossa-PR: UEPG/ PROEX, 2015. (Coleção mídias contemporâneas, v. 2).

MORÁN, J. M. Contribuições para uma pedagogia da educação on-line In SILVA, Marco. Educação online: teorias, práticas, legislação, formação corporativa. São Paulo: Loyola, 2003. p. 39-50 
MORÁN, J. M.; MASETTO, M. T.; BEHRENS, M. A. Novas tecnologias e mediação pedagógica. 19. ed. São Paulo: Papirus, 2012.

PALLOFF, R. M.; PRATT, K. Construindo comunidades de aprendizagem no ciberespaço: estratégias eficientes para a sala de aula on-line. Tradução Vinícius Figueira. Porto Alegre: Artmed, 2002.

O aluno virtual: um guia para trabalhar com estudantes on-line. Porto Alegre: Artmed, 2004.

PENTEADO, H. D. Comunicação escolar: uma metodologia de ensino. São Paulo: Salesiana, 2002.

PEREZ. F. G e CASTILLO, D. P. La mediación pedagógica. Buenos Aires: Ciccus, 1999.

PETERS, O. A educação à distância em transição: tendências e desafios. Tradução Leila Ferreira de Souza Mendes. São Leopoldo: Unisinos, 2003.

FÓRUM NACIONAL DE PRÓ-REITORES DE GRADUAÇÃO DAS UNIVERSIDADES BRASILEIRAS,12., 1999, Ilhéus-BA. Plano Nacional de Graduação: um projeto em construção. Anais... Ilhéus-BA : ForGRAD, 1999. Disponível em: <http://portal.mec.gov.br/sesu/arquivos/pdf/png.pdf >. Acesso em: 22 abr. 2012.

SANTOS, E. O. dos. Educação online: cibercultura e pesquisa-formação na prática docente. 2005. 351 f. Tese (Doutorado em Educação)- Universidade Federal da Bahia, Salvador, 2005.
SILVA, M; CLARO, T. A docência online e a pedagogia da transmissão. Boletim Técnico do SENAC. v. 33. n.2, maio-ago, 2007. Disponível em: <http://www.senac.br/ BTS/332/artigo-7.pdf>. Acesso em: 02 out. 2011.

SILVA. M. Sala de aula interativa. Rio de Janeiro: Quartet, 2001.

STAHL, G.; KOSCHMANN, T.; SUTHERS, D. Computer-supported collaborative learning: an historical perspective. In: SAWYER, R. K. (Ed.). Cambridge handbook of the learning sciences. Cambridge, UK: Cambridge University Press, 2006. p. 409-426.

TARDIF, M. Saberes docentes e formação profissional. Petrópolis: Vozes, 2002.

VIGOTSKI, L. Pensamento e linguagem. São Paulo: Martins Fontes, 1993.

VERDUIM. J. R.; CLARK, T. A. Distance education: the foundations of effective practice. San Francisco: Jossey-Bass, 1991.

YIN, R. Case study research: design and methods. 2. ed. Thousand Oaks, CA: SAGE Publications, 1994. 